\title{
Reaching Citizens' Engagement by Services: Swiss Use Case
}

\author{
Maria Sokhn *, Florian Evequoz and Arnaud Zufferey \\ Department of Informatics, University of Applied Sciences of Western Switzerland, 2800 Delémont, Switzerland; \\ florian.evequoz@hevs.ch (F.E.); Arnaud.Zufferey@hevs.ch (A.Z.) \\ * Correspondence: maria.sokhn@hevs.ch; Tel.: +41-78-908-24-29
}

Academic Editor: Muneo Kaigo

Received: 31 August 2016; Accepted: 26 October 2016; Published: 3 November 2016

\begin{abstract}
Collaboration with citizens and users plays an increasing role in the transformation of public services towards new forms of production and delivery. Thus there is a need to modernize the civil service to accelerate innovation in governments, as civil servants will also have an important role to play. Digital civic engagement platforms can provide a more attractive and accessible means for participation. We believe that neither an exclusive top-down approach nor a bottom-up approach can address the current needs. Instead a hybrid approach should be designed. This paper presents a novel approach to address the issue of current civic disengagement. This approach is illustrated through four different use cases in the Swiss context.
\end{abstract}

Keywords: citizen engagement; services; trust and transparency

\section{Introduction}

The success of new sophisticated and innovative public services depends to a large extent on the engagement of the public and/or of private sector capacities. They have to be actively engaged in collaborative settings of public service delivery. Citizens may now become developers, creators, and innovators as they use, shape, adapt and create technologies to fit their demands and needs. It is essential to understand the future in order to shape it in sustainable ways and provide the required public service. For governments, a major challenge is to reinvent governance models and public services in such a way that they match current and future trends as well as the demands of citizens.

Collaboration with citizens and users plays an increasing role in the transformation of public services towards new forms of production and delivery. Thus there is a need to modernize the civil service to accelerate innovation in government, as civil servants will also have an important role to play. Empowered, motivated civil servants with the right skills, tools and mechanisms continue to be a great asset. To that end, public authorities must have a clear and shared vision with stakeholders (executive, legislative, administration, citizens) as well as suitable management tools and communication. There is a need for new forms of cooperation between science, civil society and policy makers to address these challenges and move from silos to inter-institutional reflections. Indeed, decision-making based on evidence (evidence-based) allows taking into account experiences and new scientific discoveries, and the lessons of visionary projects. Furthermore, decisions based on participation (citizen-oriented) tend to be more durable, thus the government, given its position as the connector between politics and the citizen, is supposed to serve this with a participatory approach. Finally, information and communication technology have greatly influenced the business models of private companies. Yet the public authorities are late to address the interfaces between the citizen and public policy, open access to information and collective intelligence and the management of government with effective tools. There is a need for innovative models for the public sector. 
We believe that neither an exclusive top-down approach nor a bottom-up approach can address the current needs. Instead a hybrid approach should be designed. Digital civic engagement platforms can provide a more attractive and accessible means for participation. In order to reach this engagement, public authorities need to be pro-active by offering useful services: (1) the services should follow a transparent process; (2) these stages motivate an active participation of the citizens; (3) active participation will inspire citizen for further engagement; and (4) this will consequently feed the service design (cf. Figure 1). This paper presents our approach in Section 3, and focus on its illustration through four main use cases presented in Section 4.



Figure 1. Service based citizens' engagement: Life Cycle Approach.

\section{Background}

There is a common belief that new technologies will encourage and facilitate partnerships between citizens and civic authorities, enabling civic engagement. However, perceived value of civic engagement technologies remains low [1]. Some studies have tackled the issues that may avoid or block citizen engagement. Although a number showed a fuzzy correlation between trust and citizen engagement [2], the trust aspect seems to be a key enabler to civic engagement [3,4]. In parallel, some works have addressed civic engagement issue by making use of Geographic Information System (GIS) and/or by handling the Human Computer Interaction (HCI) aspects. In [5], the authors present seven emerging trends using location-based information as an enabler for successful citizen engagement. Indeed, as stated by the authors, when governments use map-based web or GIS mobile applications, citizens get a clearer picture of the situation at a glance and are able to better determine their personal involvement.

Current efforts to enable citizens' engagement have led to a plethora of tools and platforms, with a growing number of pervasive technologies. Several tools and platforms have been developed to communicate with, integrate and empower citizens. The aim of these platforms is to encourage and facilitate partnerships between citizens and civic authorities, enabling individuals to play a greater role. For instance Civic Lab (http:/ / www.civiclab.us/) performed over two years as a coworking space in Chicago. This space served as a meeting place, hub and educational facility. Other platforms such as Neighborland (https://neighborland.com/), Citizinvestor (http://www.citizinvestor.com/) and CitySourced (http:/ / www.citysourced.com/) were designed to report and share citizens' ideas and issues and to keep citizens in the loop of what was being done about the issues reported. Some projects focused on transparency as a key to engage citizens, for instance, the Sunlight foundation (http:/ / www.sunlightlabs.com/about) makes use of the tools of civic tech, open data, policy analysis and journalism to make their government and politics transparent to all. Some other projects focused on involving citizen in voting, such as Citinvestor, Civinomics (https://civinomics.com/corp/about) or PeakDemocracy (http://www.peakdemocracy.co/), where citizens and officials are involved in the discussions. In their work, EngagementHQ (http://engagementhq.com/) drew a spectrum to represent the means through which citizens can be informed and civic engagement can be triggered (cf. Figure 2). EngagementHQ is a digital engagement solution to help share stories, gather community feedback and analyze stakeholder needs. 


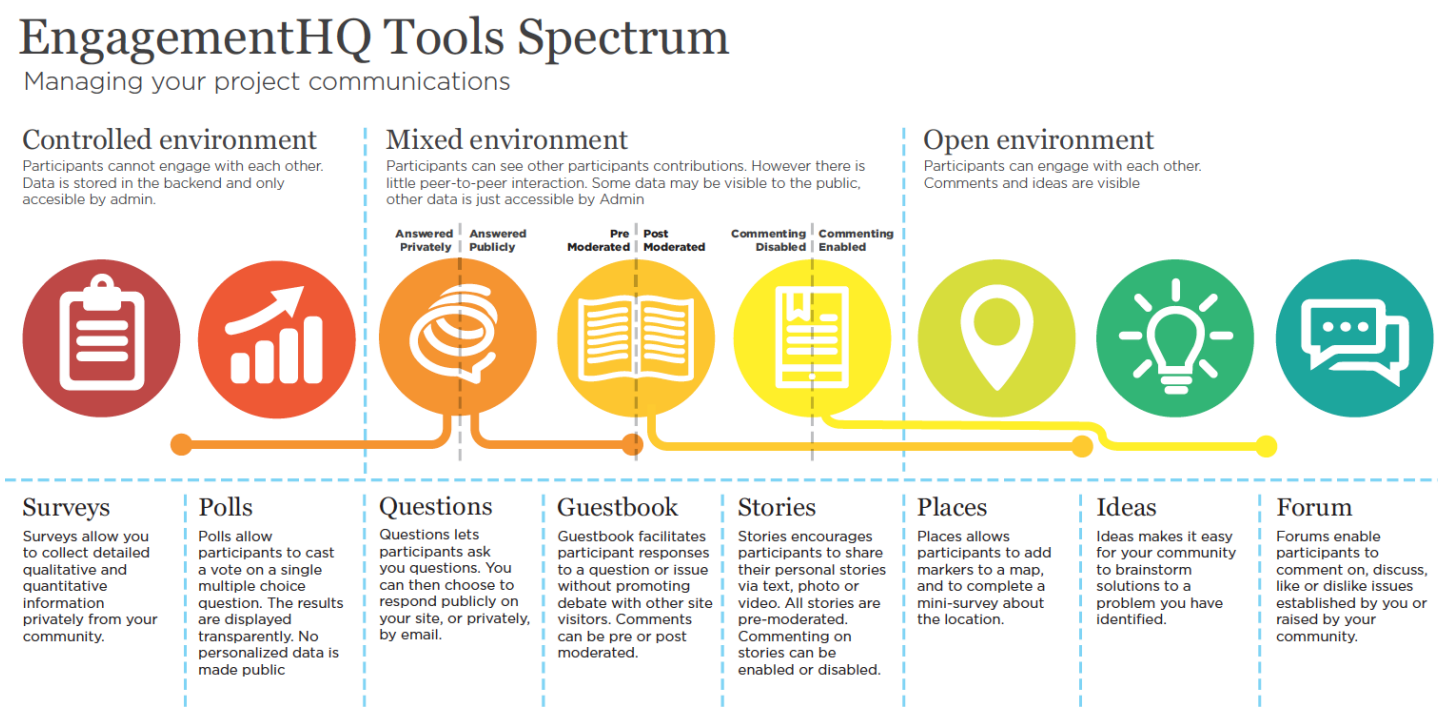

Figure 2. Project communication spectrum [6].

"Current state-of-the-art civic engagement technologies fall short in motivating citizens to effectively contribute information that civic authorities are willing to trust and act upon, and will continue to remain unpopular unless inherent aspects of mistrust that exist are addressed in the design process" [1]. We believe that civic engagement platforms can provide a more attractive and accessible means for participation only if both citizens' and authorities' requirements are considered.

Haering [7] developed a process to confront the global challenges that Switzerland will also face. These challenges can be social, financial, environmental, etc., which will directly impact the decision makers who are expected to take the right actions at the right time. Different approaches have been discussed so far. In this paper we will focus on data put into perspective, on the one hand, and data transparency and openness, on the other hand. The public sector plays a key role in maintaining social cohesion; therefore public policy must be based on and guided by values (value-based, value-oriented). Moving from a management based on expenditure to a management based on goals defined by the policies strengthens the strategic approaches and allows performance evaluation (objective-based). In addition, decision-making based on evidence (evidence-based) allows taking into account the experience, new scientific discoveries, and lessons from visionary projects. There is a need for new forms of cooperation between science, civil society and decision-makers in order to address these challenges and move from silos reflections to "trans-institutional" reflections. Moreover, decisions based on participation (citizen-oriented) tend to be more sustainable, and public authorities, given their position as the connection between politics and the citizen, are supposed to serve the citizen with a participatory spirit. Finally, information and communication technologies have greatly influenced the business models of private companies, but the public sector is late to address the interfaces between the citizen and public policy, open access to information and collective intelligence, and the management of public authorities with effective tools. There is a need for innovative models for the public sector (e-support). This description of the efficiency of administrations to address current problems and to make optimal decisions encourages us to propose this project that will engage the relevant administration in a process of decision-making, based on evidence, participation and innovation.

\subsection{Data Put into Perspective}

In their industrial report, TDWI Research [8] concludes that operational efficiency is the major benefit sought by companies during the implementation of data visualization by reducing the time needed for their users to access and analyse data. Visualizations used can serve different purposes: 
to show the state of the organization at some point in relation to its performance indicators (e.g., with dashboards), to alert following a change in the data, or to visually explore and analyse data. Shapes of visualization are varied, such as bar plots, pie charts, scatter plots, line plots, maps, etc. There are several visualization solutions that are available in overall solutions (analysis + visualization) or frameworks and development tools for visualization projects. In the first category, for example, we quote: Knime, SAS, SQL Server BI, R, etc. In the second category we find data visualization frameworks such as: d3.js, Protovis, Google charts, etc. Specifically, visualization shaped into interactive dashboards remains the most popular among businesses. A successful case of their use for decision-making at Procter and Gamble was presented in [9]. "Decision Cockpit" is the "single source of truth" at Proctor and Gamble. As described in [10], a dashboard is a visual display of consolidated information on a single screen, to monitor the information and make instant and informed decisions. Dashboards allow monitoring critical business processes when performance does not meet the objectives, identify and manage sources of problems and manage processes and resources to optimize decision making [11]. An exploratory study has validated the interest in this kind of dashboard in the field of energy management with municipalities in the canton of Valais [12]. The study found that municipal officials often face a lack of information when taking decisions, lack of operational tools to support these decisions and monitoring the management process. It also noted the discrepancy between cantonal policies and the real needs of municipalities.

\subsection{Data Transparency}

On the other hand, the concept of transparency has emerged in recent decades as a need to address organizational and individual aberrations. In their paper [13], Pasquier et al. identified four types of transparency: documentary (access to information), organizational (knowledge of the organization and its operation), accounting and budget (origin of the funds and their use), administrative actions and responsibilities (explaining the meaning of decisions). The study also established a typology of organization's behaviors with respect to transparency requirements. It concludes that, to ensure transparency, a profound cultural change has to be operated within administrations. The behavior analysis will identify measures to be implemented into administrations to support a process towards greater transparency. Furthermore, what we must focus on is the purpose of transparency and not transparency for transparency' sake. To support this vision of transparency, one of the measures taken by governments worldwide is to create an "open data" policy. Open data, or "opened data", is a concept in which information can be freely used, reused and distributed by anyone, provided the source is mentioned and rebroadcast the information with the same license as the original information. According to [14], the issues of reuse of public data are varied: political (transparency, modernization), economic (added value estimated at 140 million euro per year) and legal (copyright, personal data).

Another challenge for the Swiss municipalities is the cost of open data at the research level and the census of reusable data, cleaning and treatment, the cost of developing a portal of publications, human resources and financial resources to get there. Several types of data can be reused and published in a public sector such as administrative documents (minutes of meetings, permits, discussions, etc.), geographic data (maps, land registers, etc.), financial information (budgets, statistics, subsidies, etc.), or even the analyses that have been made to these municipalities (e.g., energy dashboards, etc.). The main players in open data are data producers, re-users and consumers. In addition, for an open data set to be useful and reusable it should be complete, primary (raw with minimal aggregation), timely, accessible, usable, non-discriminatory, non-proprietary and royalty free. There are a number of platforms of open data, for instance: CKAN, a free platform to make data accessible by providing tools to organize the publication, sharing, searching or reuse of data; DataHub, based on CKAN, is used to share the data sets of the Linked Open Data. Examples of open government data platforms exist in the US, UK, and Switzerland. In this goal of promoting transparency, the project aims to support municipalities in their data opening process by providing the tools for managing and sharing data in the form of a platform and a portal. 


\section{Approach}

The proposed work develops an innovative approach to reinvent public services to support modernization. Technically it aims at a framework service to enable stakeholder-led innovation in public services. Its major strength is that it can be used across all public services, both electronic (e-government, mobile-government) and non-electronic. Figure 1 presents our approach, where we start by proposing services at different levels: citizen, public authorities and city. These services offer citizens a simple way of being informed, on the one hand, and to participate and thus civically being engaged, on the other.

As stated above, in our work we focus on enhancing the transparency and efficiency in Swiss public authorities, by making use of collected data based dashboards. The structure of Swiss public authorities in the current situation can be represented as shown in Figure 3. In this configuration, the different members of the public body at both strategic and operational levels will not share the information. This situation leads to no transparency, subjective viewpoints, "feeling-driven" decision-making, and inefficiency. We propose to make use of dashboards (Figure 4), which will allow different stakeholders to share the same picture of the situation. This sharing will facilitate the dialogue between the different politics party, and it will help the convergence of objectives. In a first phase these dashboards will be available at public authorities to target only the efficiency of internal operations. The actors of these public authorities could then decide to include, for example, these dashboards in the reports presented at the primary assemblies. In a third step, data and dashboards could be offered to citizens before meetings so that they can take full knowledge and better prepare their questions (open data, Figure 4). In a later stage, the citizens would have the means to contribute to the political implementation by taking advantage of the open data in order to propose open innovation services.

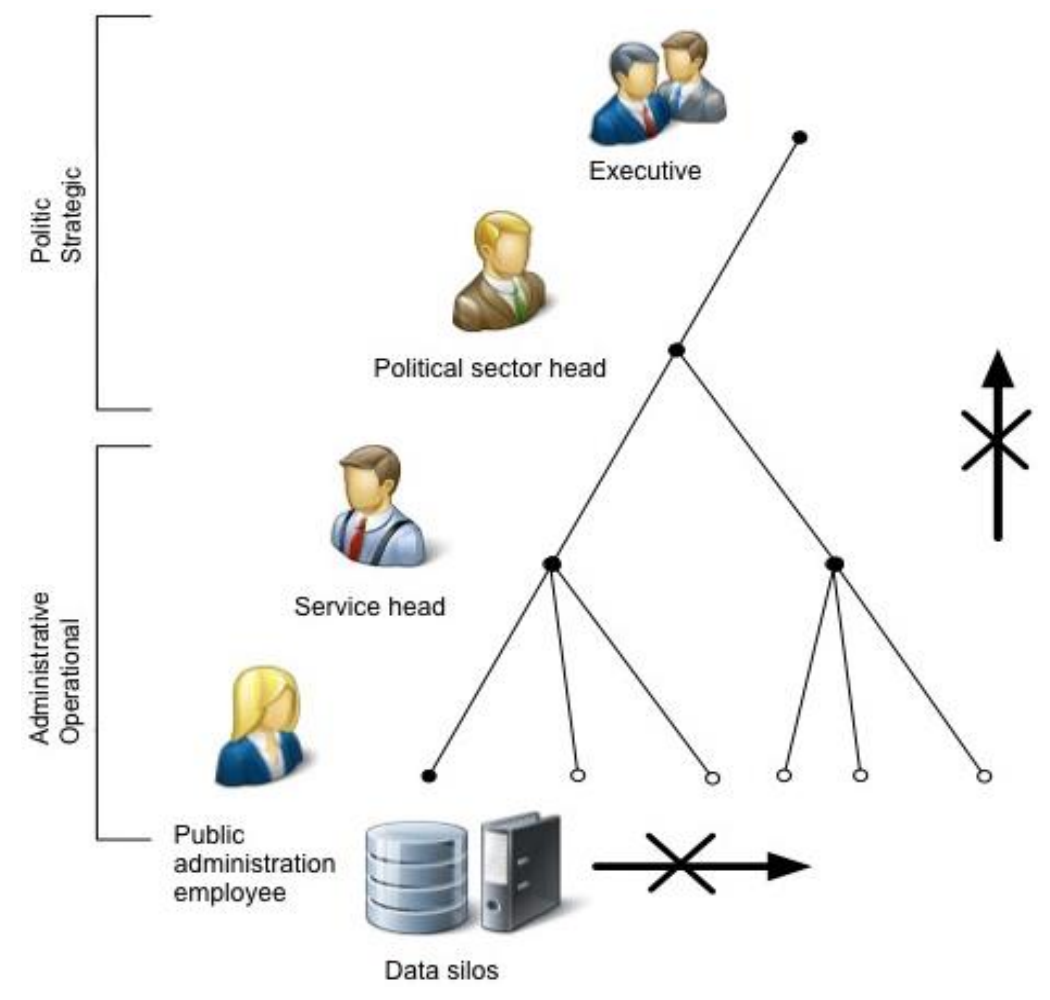

Figure 3. Current situation. 


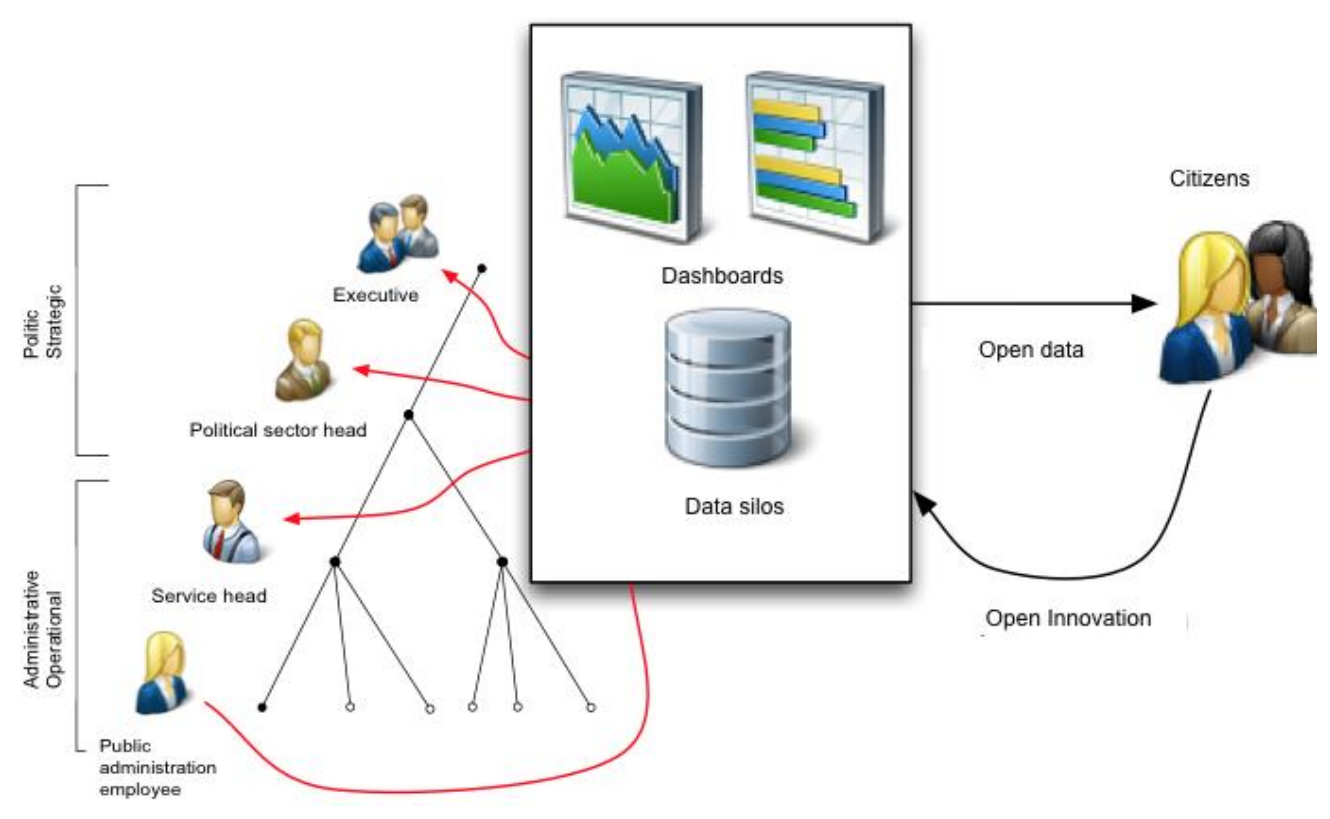

Figure 4. Situation with civic engagement.

\section{Use Cases}

To illustrate our approach presented so far and insights on the issues that shape the engagement this section presents four main use cases. These services fall in different categories: those that inform, allowing to identify challenges, those that propose novel aspects of public service, those that will engage participation and evaluation, and finally those useful for decisions.

\subsection{Citizen Oriented Services-Smart Invoices Use Case}

The smart meters are being spread in houses, and clients are being increasingly connected. However, there are currently few tools that grasp the information of these so-called counters, and which offer their consultation over a single platform that puts into perspective real time and multi-fluid energy related data. The "smart metering client" use case (Figure 5) aims to develop an interactive and ergonomic platform available on different devices (PC, Smartphones, Tablets, etc.) for visualizing energy related data. The goal of this platform is to provide monitoring of the consumption and production of several buildings, and several flows: heat, electricity, photovoltaic, water and gas. A responsive website that complies with the requirements has been developed, providing account management, and offering a monitoring of the power consumption of a pilot building over a graph (cf. Figure 6). A system of notifications (e-mail and SMS) is integrated into the site, and a map showing the locations of various buildings (cf. Figure 7).

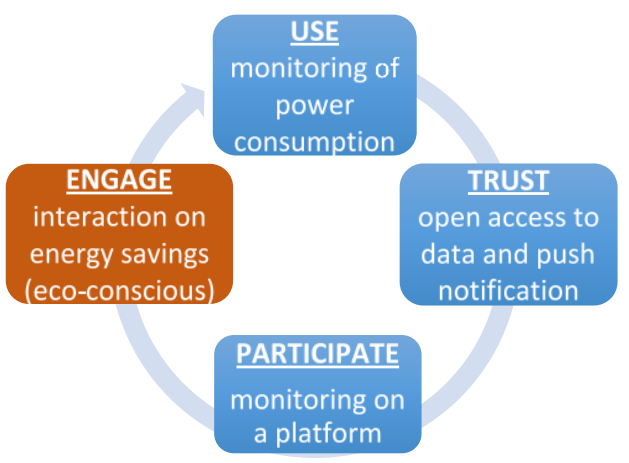

Figure 5. Smart invoices use case life cycle. 
Suivi de la consommation

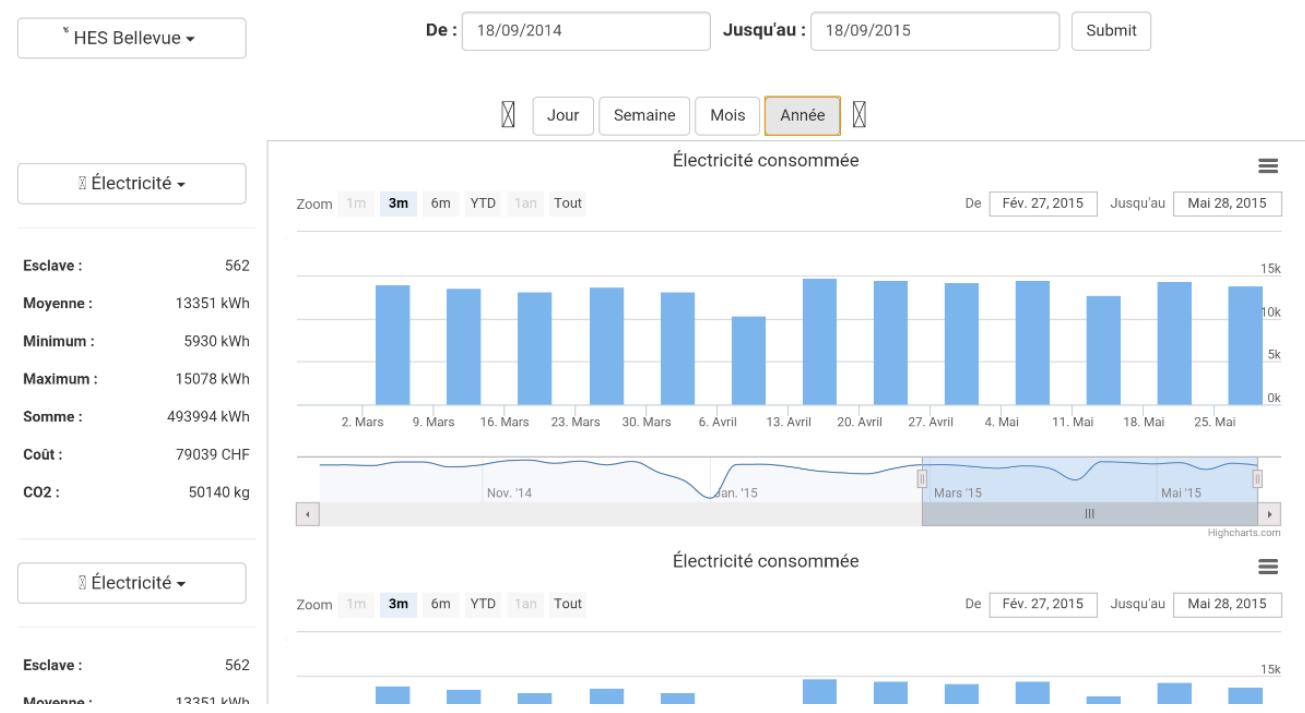

Figure 6. Smart metering interface.

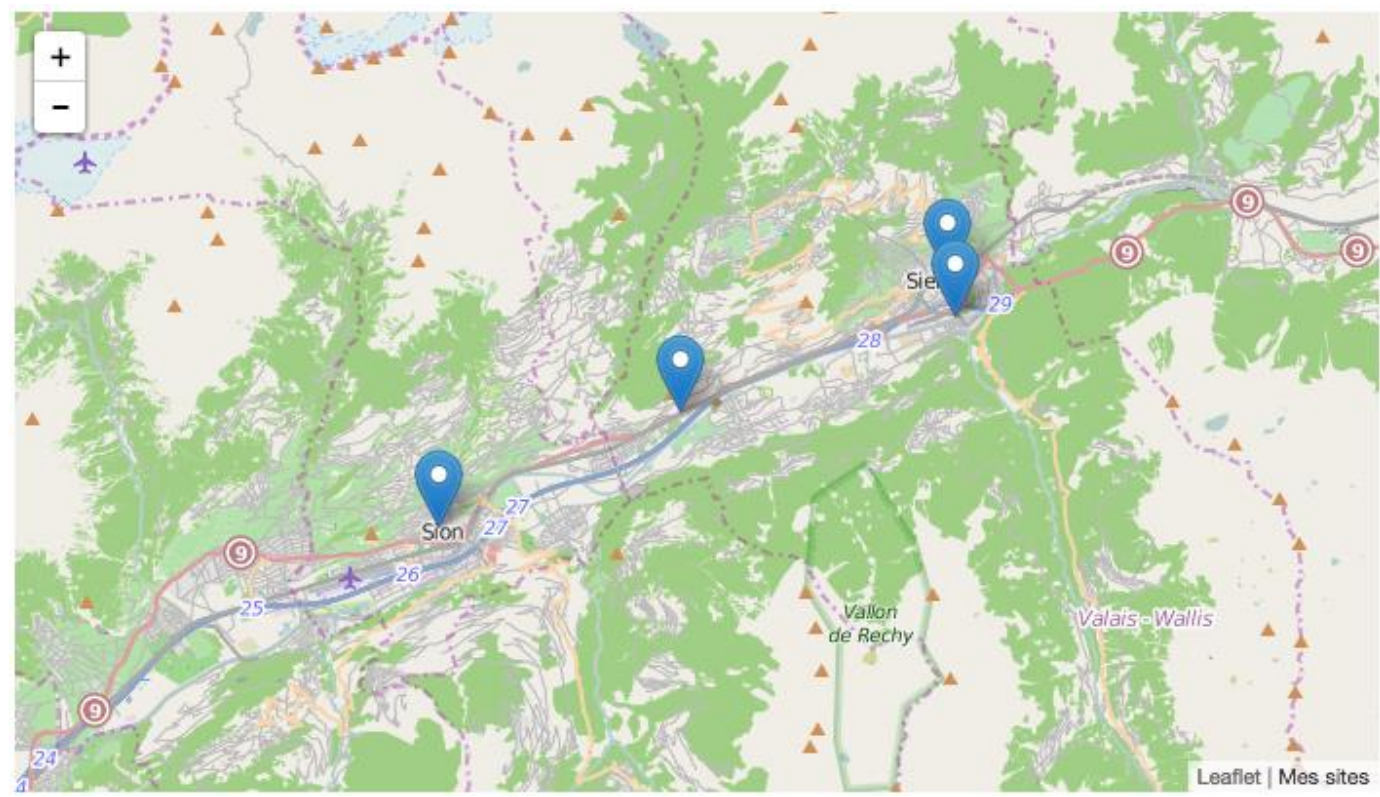

Figure 7. End-users geolocalised buildings.

This "smart metering client" service implemented offers the following main features:

- Visualize indicators (consumption and production of electricity, gas, water) over a predetermined period (last day, last week) to see and understand consumption/production of energy over a defined period;

- Visualize the position of my buildings on a map to see where the buildings are located of which I would like to know consumption;

- See predicting indicators for the next day to anticipate consumption the next day, setting up the basis for a game/challenge; 
- Set my preferences for notifications (SMS, e-mail) and be able to choose the frequency and notifications channel to adapt to my needs;

- Receive regular notifications with indicators (annual and monthly virtual invoice, weekly accounts, daily balance) to monitor without having to connect to the platform;

- Export a time series CSV (comma separated values) to be used in other software (Excel, etc.).

The citizen, being aware of the details of the invoices, and having this information in a transparent way, will be most likely willing to participate in the energy saving strategy.

\subsection{Public Authorities Service—Prediction of Renewable Energy Use Case}

Another service that we developed is the "prediction of renewable energy" (Figure 8) [15]. The aim is to provide a forecasting model to set the day-ahead grid electricity need. To that end we analyse the time series on historical predictions to correct the forecasted data given by meteorological services. This information is important since the ability to predict variable sources based on meteorological uncertainty enhances considerably the management of the energy supply needs and reserves. We provide an approach that combines classification algorithms to predict photovoltaic plant efficiency (based on weather conditions), and nonlinear regression to predict weather forecasted errors. The implemented methodology respects the following steps: data pre-processing (weather forecast and real measures photovoltaic production); training (clustering inputs of hours temperature measures, and decisions tree training inputs); alpha prediction (decision tree predictor inputs); weather forecasting error prediction (polynomial regression); production prediction (daytime prediction and night, power prediction calculation).

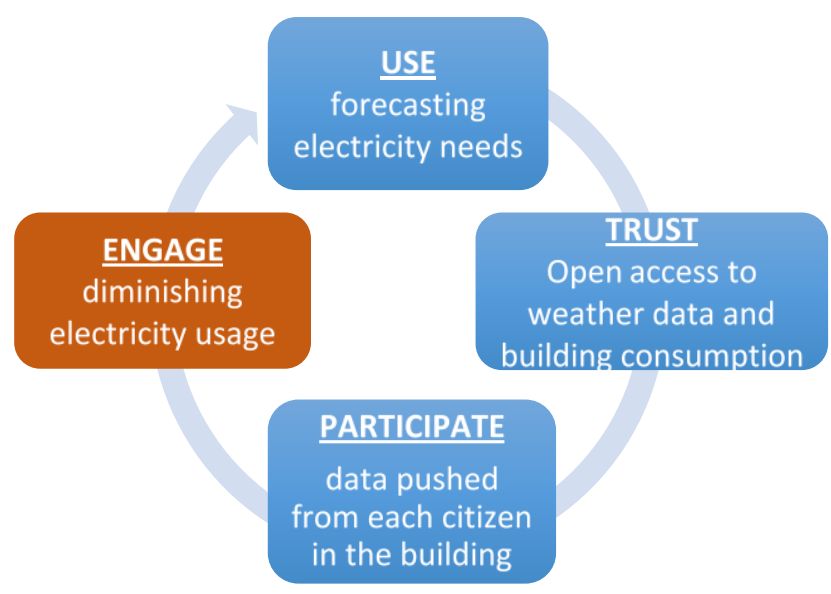

Figure 8. Prediction of renewable energy use case life cycle.

Our experiment was based on a pilot building. The best experimental results were obtained using hourly historical weather measures (radiation and temperature) and photovoltaic production as training inputs and weather forecasted parameters as prediction inputs. Considering a ten-month dataset and despite the presence of 17 missing days, we achieve a percentage mean absolute deviation of $20 \%$ in August and $21 \%$ in September. Figure 9 presents a screenshot of the renewable energy prediction interface dedicated for the responsible of the photovoltaic prediction in the pilot building. It shows the results of the pilot applied to a real energy distributor use case. The citizens concerned with this information where more carful afterwards to their consumption and were engaged to find solution to reduce their electricity usage. This could be considered as an indirect civic engagement; still, we believe that without this service, the citizens would not have engaged effort and time in optimizing energy consumption. 


\section{Photovoltaïque}



\begin{tabular}{llll} 
& Mesure hier (J-1) & Prevision aujourd'hui $(\mathbf{J})$ & Prevision demain $(\mathbf{J + 1})$ \\
\hline Predicted Production Average & $0.227 \mathrm{MWh}$ & $0.289 \mathrm{MWh}$ & $0.299 \mathrm{MWh}$ \\
\hline Predicted Production & $8.870 \mathrm{MWh}$ & $11.260 \mathrm{MWh}$ & $11.666 \mathrm{MWh}$ \\
\hline Production Average & $0.279 \mathrm{MWh}$ & - & - \\
\hline Production & $10.879 \mathrm{MWh}$ & - & - \\
\hline RMSE & 0.123 & - & - \\
\hline Min & $0.000 \mathrm{MW}$ & - & - \\
\hline Max & $0.856 \mathrm{MW}$ & - & - \\
\hline Min predicted & $0.000 \mathrm{MW}$ & $0.000 \mathrm{MW}$ & $0.000 \mathrm{MW}$ \\
\hline Max predicted & $0.830 \mathrm{MW}$ & $0.849 \mathrm{MW}$ & $0.849 \mathrm{MW}$ \\
\hline
\end{tabular}

Figure 9. Photovoltaic prediction.

\subsection{Parliament Services-Legislative Work Visualization}

The cantonal parliament of Valais publishes online all the documents produced by the work of its Members of Parliament (MPs). These are typically motions and interventions during the sessions, which are usually co-signed by several MPs. Besides their main content, these documents are tagged with a specific topic (out of a dozen) and the name of their authors. On the parliament website, all those documents can be found on the personal page of each author MP.

In order to raise public awareness about the work of the parliament, political parties, and individual MPs, we developed a prototype that makes use of this corpus of documents to provides data visualizations and to enable browsing the corpus according to three complementary perspectives (Figure 10):

- Topic perspective: topics are ranked according to their importance (i.e., the number of documents related to the topic). In a specific topic page, the top MP and political parties interested in the topic are presented, and individual documents can be accessed.

- MP perspective: MPs are presented along with their statistics, i.e., the number of documents they co-signed during the period. Specific MP page presents the MP, their main topics of interest, as well as the "similar profile" MP, i.e., other MPs interested in the same topics, with a similarity score. 
- Parties perspective: similarly to the above, the main parties page present all parties, with their topics of interest, allowing the user to compare the relative importance of each topic for each party. In a specific party page, top MPs of the party are presented.

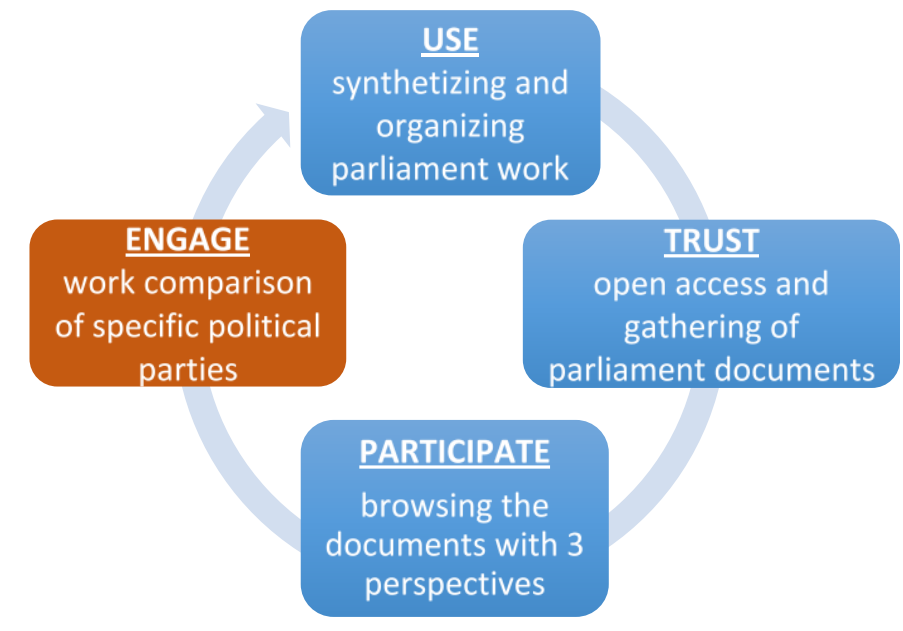

Figure 10. Legislative work visualization life cycle.

Preliminary feedback received on the prototype implementation by members of political parties, journalists and citizens indicates a strong interest in the approach, as it provides both a bird's eye vision of the parliament work, and allows the comparison of specific parties and MPs, therefore improving transparency of the parliamentary work. Accessing this data is a first step for citizen in the engagement lifecycle. Indeed, being able to easily access and browse documents will help citizens by reducing their effort in analysing existing information.

\subsection{City Oriented Services-City-Stories}

City-Stories aims to provide an open platform that empowers citizens by offering an interactive and semantic way to store and integrate spatio-temporal knowledge, and to exploit these enriched data and knowledge by novel search, browsing, and visualization support so as to valorise their cultural heritage (Figure 11). In order to provide this novel spatio-temporal crowdsourced content platform, City-Stories needs to rely on a database which contains the integrated information coming from various sources such as linked open data, user-provided data (e.g., ratings, photos), geo-spatial data, temporal data and multimedia data (heterogeneous data integration, linking mapping and cleaning). Its core is a database with a spatio-temporal data model with a sophisticated index structure that supports the different query types identified above (knowledge based querying and browsing). It relies also on a set of data visualization approaches, and knowledge browsing and visualization (personalized data and information visualization). From a high-level perspective, the City-Stories platform is composed of three main modules:

- Data integrator module responsible of gathering distributed and heterogeneous data and offering data alignment, mapping and cleaning;

- Retrieval engine that stores combined and semantically enriched data and metadata in order to serve as basis for advanced spatio-temporal and personalized queries;

- Knowledge crowdsourcing and visualization module that offers an adaptive and profile aware crowdsourcing and knowledge visualization and navigation interface. 


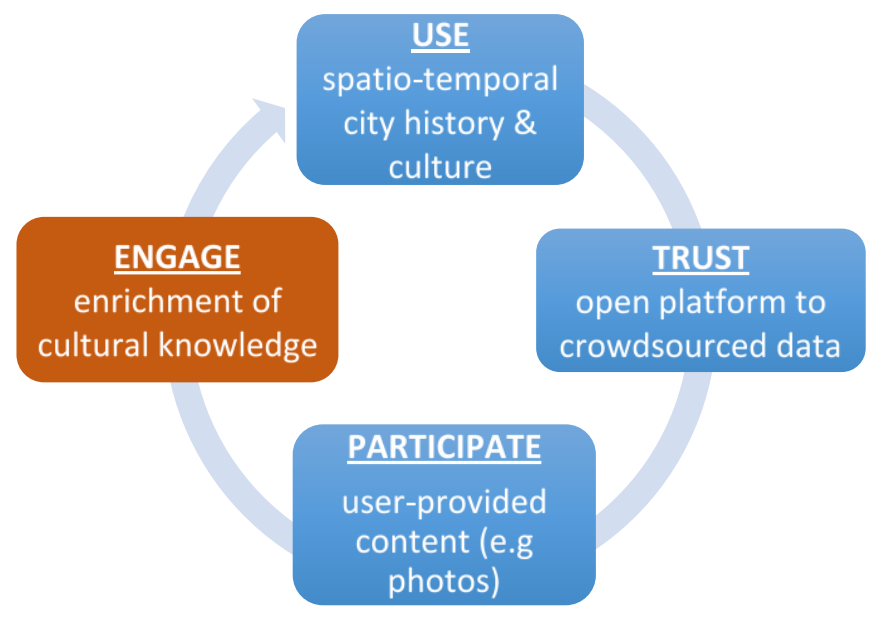

Figure 11. City-Stories life cycle.

City-Stories is significant to citizens whether they are tourists or local residents. It offers them a platform for knowledge sharing and cultural heritage valorisation. Indeed the development of the tourism industry has been marked in recent years by the synchronization and flexibility of social time. Tourists favour short stays focussed on rural towns' open space. These new tourist flows are major resources for regional development, particularly in urban areas. Tourists are no longer exclusively interested in religious buildings or remarkable political or military sites; the entire neighbourhoods are now the subject of beautification strategies whose aim is to increase their attractiveness.

City-Stories is highly significant to every resident of any city or village who would like to participate in the knowledge sharing and the enhancement of the attractiveness of his or her city or village. City-Stories empowers the citizen, firstly, by offering them an integrated platform that gather yet unexplored knowledge, and secondly, by fostering automatic annotation and linking data with existing information.

\section{Conclusions}

We believe that neither an exclusive top-down approach nor a bottom-up approach can address the current needs. Instead a hybrid methodology should be designed combining top-down and bottom-up approaches. The civic engagement platforms can provide a more attractive and accessible means for participation only if both citizens' and authorities' requirements are considered. Through our work in the different use cases we observed a service process that we describe in the Figure 12. We also observed the causal effect of accessing the data with citizens' engagement. The "civic engagement white paper series" supports the data-related facets of civic engagement in cities, and asserts, "more cities are beginning to turn to data and technology to streamline and improve their civic engagement, allowing them to connect with more residents in a more efficient manner" [16]. We presented a life cycle approach based on citizens' engagement through transparent and useful services. This approach may not be applicable in other countries, yet the hybrid approach may be replicable. In our future work we aim to consolidate our hypothesis and evaluate the result with citizens and public administration. 




Figure 12. Service process.

Acknowledgments: We would like to thank the Hasler Stiftung (http://www.haslerstiftung.ch/en/) for the funding granted to the city-stories work. The RCSO-Isnet for the funding granted for the "Smart Invoices" and "Predection of renewable Energy". We would like to thank Yvan Bétrisey from the Icare Institut (https://icare.ch/) for his involvement in the work related to the Prediction of Renewable Energy Use Case. Our thanks go to Alexandre Cotting for the design of the Figures 3 and 4, which were used in this paper.

Author Contributions: Maria Sokhn proposed the life cycle approach, she worked on the city stories use case and wrote the major parts of the paper. Florian Evequoz worked on the parliament service use case and wrote the related section. Arnaud Zufferey worked on the uses cases "Smart Invoices Use Case" and "Prediction of Renewable Energy Use Case" and delivered the necessary information and data to write this manuscript. All authors have read and approved the manuscript.

Conflicts of Interest: The authors declare no conflict of interest.

\section{References}

1. Harding, M.; Knowles, B.; Davies, N.; Rouncefield, M. HCI, Civic Engagement \& Trust. In Proceedings of the 33rd Annual ACM Conference on Human Factors in Computing Systems, Seoul, Korea, 18-23 April 2015; pp. 2833-2842.

2. Van Ingen, E.; Bekkers, R. Generalized Trust through Civic Engagement? Evidence from Five National Panel Studies. Polit. Psychol. 2015, 36, 277-294. [CrossRef]

3. Salim, F.; Haque, U. Urban computing in the wild: A survey on large scale participation and citizen engagement with ubiquitous computing, cyber physical systems, and Internet of Things. Int. J. Hum. Comput. Stud. 2015, 81, 31-48. [CrossRef]

4. Lam, B.; Chen, Y.P.; Whittle, J.; Binner, J.; Lawlor-Wright, T. Better Service Design for Greater Civic Engagement. Des. J. 2015, 18, 31-55. [CrossRef] 
5. 7 Emerging Trends in Citizen Engagement. Available online: https://www.esri.com/ /media/Files/Pdfs / industries/gov20/pdfs/7-emerging-trends.pdf (accessed on 22 October 2016).

6. EngagementHQ: What Tool for What Purpose? Available online: https://bangthetable.zendesk.com/hc/enus/articles /210563866-What-tool-for-what-purpos (accessed on 28 October 2016).

7. Haering, B. Future Challenges for Public Administrations and Their HR Development. Available online: http:/ / www.barbara-haering.ch/sustainable-development-and-public-sector-reform/Challenges_ for_Public_Administrations_Taipei_2012.pdf (accessed on 29 October 2016).

8. Stodder, D. Data Visualization and Discovery for Better Business Decisions. Available online: http://www.pentaho.com/sites/default/files/uploads/resources/data_visualization_and_discovery_ for_better_business_decisions.pdf (accessed on 22 October 2016).

9. Charts, F. Towards Effective Decision-Making through Data Visualization: Six World-Class Enterprises Show the Way. Available online: http://www.fusioncharts.com/whitepapers/downloads/Towards-EffectiveDecision-Making-Through-Data-Visualization-Six-World-Class-Enterprises-Show-The-Way.pdf (accessed on 22 October 2016).

10. Few, S. Dashboard Confusion. Available online: https://www.perceptualedge.com/articles/ie/dashboard_ confusion.pdf (accessed on 27 October 2016).

11. Wayne, W.E. Performance Dashboards, Measuring, Monitoring and Managing Your Business; John Wiley \& Sons: Hoboken, NJ, USA, 2011.

12. Sokhn, M.; Cotting, A.; Evéquoz, F.; Zufferey, A. From Data to Decisions. In Proceedings of the 9th International Conference on Theory and Practice of Electronic Governance, Hammamet, Tunisia, 1-3 March 2016; pp. 361-362.

13. Pasquier, M.; Villeneuve, J.P. Transparence et Accès à L'information; IDHEAP: Lausanne, Switzerland, 2005. (In French)

14. Uské, T. Linked Open Data: Enjeux Opportunités Pour les Services Publics; Technical Report for Master of Science HES-SO en Business Administration-diplômé-e-s 2014; Orientation Management des Systèmes d'information: Delémont, Switzerland, July 2014. (In French)

15. Barque, M.; Dufour, L.; Genoud, D.; Zufferey, A.; Ladevie, B.; Bezian, J. Solar production prediction based on non-linear Meteo source adaptation. In Proceedings of the 20159 th International Conference on Innovative Mobile and Internet Services in Ubiquitous Computing (IMIS), Blumenau, Brazil, 8-10 July 2015.

16. Schrimmer, D. Case Study of 21st-Century Civic Engagement; Data-Smart City Solutions: Cambridge, MA, USA, 2015. 